\title{
TÁCITAS E MARGINAIS: MEMÓRIAS DAS CASAS DE ESTUDANTE AUTÔNOMAS DE PORTO ALEGRE E AS POSSIBILIDADES PARA A HISTÓRIA DA EDUCAÇÃO \\ DOI: http://dx.doi.org/10.1590/2236-3459/68750
}

\author{
Marcos Luiz Hinterholz \\ Universidade Federal do Rio Grande do Sul, Brasil.
}

$\cos 8$

\section{Resumo}

A temática da moradia estudantil universitária ainda é pouco abordada pela historiografia, o que pode ser decorrente da redução destes espaços ao seu caráter assistencial, em abordagens que não as contemplam enquanto lugar de formação e de troca de saberes. Pretende-se, a partir de perspectivas abertas pela vertente da História Cultural, apresentar o surgimento e organização de três casas de estudantes autônomas de Porto Alegre e discutir a inscrição deste tema no campo da História da Educação. Busco ainda pensar fontes e algumas questões importantes para pesquisas relacionadas a este tema.

Palavras-chave: casas de estudante, autonomia e autogestão, história da educação.

\section{TACIT AND MARGINAL: MEMORIES OF AUTONOMOUS STUDENT HOUSES IN PORTO ALEGRE AND THE POSSIBILITIES FOR THE HISTORY OF EDUCATION}

\begin{abstract}
University student housing as a locus of research is a relatively new theme in historiography, mostly due to narrow understandings that frequently reduce these places to their assistance character, rather than address them as sites of training and knowledge exchange. Based upon a Cultural History approach, this paper will analyze the origins and organization of three autonomous student houses in Porto Alegre/Brasil, arguing for the inclusion of this topic in the field of History of Education, discussing research resources and proposing some important questions for future studies .

Keywords: student houses, autonomy and self-management, education history.
\end{abstract}




\section{TACITAS Y MARGINALES: MEMORIAS DE LAS VIVIENDAS AUTÓNOMAS \\ DE ESTUDIANTES DE PORTO ALEGRE Y LAS POSIBILIDADES PARA LA HISTORIA DE LA EDUCACIÓN}

\section{Resumen}

El tema de las viviendas estudiantiles universitarias todavía no es muy abordada por la historiografía y puede ser debido a la reducción de estos espacios a un carácter de asistencia, en enfoques que no las contemplan como un lugar de formación y de intercambio de conocimientos. Se pretende, a partir de perspectivas del rubro de la Historia Cultural, presentar el surgimiento y la organización de tres viviendas autónomas de estudiantes de Porto Alegre/Brasil y discutir la inclusión de este tema en el campo de la Historia de la Educación. Pienso buscar todavía fuentes y algunas interrogantes importantes para investigaciones relacionadas con este asunto.

Palabras-clave: viviendas de estudiantes, autonomía y autogestión, historia de la educación.

\section{TACITES ET MARGINALES: MEMOIRES DES RESIDENCES UNIVERSITAIRES AUTONOMES DE PORTO ALEGRE ET LES POSSIBILITES POUR L'HISTOIRE DE L'EDUCATION}

\section{Résumé}

La question de la résidence universitaire est encore peu étudiée par l'historiographie, celapossiblementà cause de la perspective d'assistanat concernant ces espaces, d'après des apporoches qui leur excluent le statut de lieu de formation et d'échange de savoirs. À partir de quelques perspectives ouvertes par la branche de l'Histoire Culturelle, on prétend présenter la création et l'organisation de trois résidences universitaires à Porto Alegre/Brésil et penser l'inscription de ce thème dans le champ de l'Histoire Culturelle de l'Éducation. En plus, je cherche de réfléchir sur les sources et sur quelques questions importantes concernant les recherches liées à la question de la résidence universitaire.

Mots-clé: résidence universitaire, autonomie et autogestion, histoire de l'éducation. 


\section{Introdução}

A História da Educação, na perspectiva da História Cultural, ampliou as temáticas que abrangem espaços, instâncias e atores não formais dos processos educativos. Estas abordagens são possíveis graças aos encontros que se processam com a antropologia, a linguística, a literatura e a psicologia, por exemplo. O resultando são novos olhares e novos instrumentos conceituais e o refino analítico dos novos objetos. Deste modo, as concepções epistemológicas que deram à cultura centralidade, ou pelo menos grande relevância na análise do social, também expandiram sobremaneira o que se entende por pedagógico.

Os contornos e ênfases das pedagogias que estão em operação na atualidade têm se multiplicado, "com o deslocamento de uma sociedade centrada no ensino para uma sociedade da aprendizagem" (Castro; Costa, 2013, p. 23). Há uma pluralidade de pedagogias existentes, discussões que despontam, por exemplo, nas pesquisas desenvolvidas sob a perspectiva dos estudos culturais, permitindo temáticas periféricas ou fora dos espaços educativos formais:

Do enfoque no ensino-aprendizagem, marcadamente concentrado no interior de espaços escolares, observa-se um crescente deslocamento para análises e debates que sinalizam o quanto as aprendizagens ocorrem em diversificados espaços e artefatos que circulam, transcendem e também atravessam a escola. (p. 23)

Também Magalhães (2004) expandiu os conceitos de instituição educativa e sistema educativo para além do escolar, identificando nas sociedades e existência de organizações que se apresentam de formas diferenciadas e hierarquizadas, sendo, no entanto, todas elas educacionais. Enumera o que chama de instituições de base, como a família, a tribo, a seita ou a cooperativa; as de formação, como as escolas, internatos, colégios, associações de antigos alunos; as de produção e mobilização, como confrarias, lojas maçônicas, partidos políticos; as de produção e distribuição, como empresas, condomínios e, por fim, as que chama de holísticas-integrativas, constituidoras de fator de identificação e diferenciação, como sociedades, associações fundações e bairros.

Já o sistema educativo seria um todo mais amplo, que comporta e integra asdiferentes instituições educativas ${ }^{1}$. Cada uma destas instituições é possuidora de uma realidade institucional, ou seja, atores sociais, condições materiais e financeiras, produtos materiais e simbólicos, identidades, processos e contextos históricos e políticos nos quais nascem, se mantem ou se extinguem. Todas as instituições ocupam uma posição dialógica neste sistema educativo, posição esta que pode ser melhor compreendida ou explicada pela História da Educação, e dentro dela, mais especificamente, pela história das instituições educativas (Magalhães, 2004).

\footnotetext{
1 "A história do sistema educativo não é um somatório de instituições escolares justapostas nem, por outro lado, a história de uma dessas instituições se torna possível fora de um todo coerente. É nos domínios da representação e da apropriação que esta autonomização se revela mais consequente, porque mais relacional e menos concentrada. Constituindo um todo em si mesma, cada instituição escolar ou educativa integra esse todo mais amplo que é o sistema educativo" (Magalhães, 2004, p.114). 
Nesta perspectiva, buscarei apresentar três das sete casas de estudante de Porto Alegre, notadamente as que se mantêm de forma autônoma ${ }^{2}$, conforme o quadro 1 , e discutir a inscrição desta temática no campo da História da Educação, refletindo sobre o seu potencial como objeto de pesquisa. A proposta tem como perspectiva a necessidade de uma contextualização mais ampla destas instituições, com vistas a um melhor entendimento de como elas nascem, se organizam e se mantêm, além de superar a visão destas casas como pertencentes ao domínio da assistência estudantil, ampliando seus significados na direção dos aspectos formativos e políticos destas coletividades.

Quadro 1 -

Casas de estudante de Porto Alegre/RS.

\begin{tabular}{|c|l|c|c|}
\hline Mantenedora & \multicolumn{1}{|c|}{ Instituição } & Fundação & Gestão \\
\hline Autônoma & $\begin{array}{l}\text { Casa do Estudante Universitário } \\
\text { Aparício Cora de Almeida - Ceauca }\end{array}$ & 1934 & Autogerida \\
\cline { 2 - 4 } & $\begin{array}{l}\text { Casa Estudantil Universitária de } \\
\text { Porto Alegre - Ceupa }\end{array}$ & 1950 & Autogerida \\
\cline { 2 - 4 } & $\begin{array}{l}\text { Associação Casa de Estudantes } \\
\text { Juventude Universitária Católica } \\
\text { Casa 7 - JUC-7 }\end{array}$ & 1949 & Autogerida \\
\hline \multirow{6}{*}{ Ufrgs } & $\begin{array}{l}\text { Residência das Alunas da Escola de } \\
\text { Enfermagem da Ufrgs }\end{array}$ & 1950 & Extinta \\
\cline { 2 - 5 } & $\begin{array}{l}\text { Casa da Estudante Universitária do } \\
\text { Rio Grande do Sul - Ceurgs, atual } \\
\text { Ceufrgs }\end{array}$ & 1956 & Autogerida \\
\cline { 2 - 5 } & $\begin{array}{l}\text { Casa do Estudante das Faculdades } \\
\text { de Agronomia e Veterinária }\end{array}$ & 1960 & Autogerida \\
\cline { 2 - 5 } & $\begin{array}{l}\text { Casa do Estudante Universitário - } \\
\text { CEU }\end{array}$ & 1971 & Ufrgs \\
\hline
\end{tabular}

Fonte: Elaborado pelo autor.

A legitimação de tal abordagem, no entanto, não ocorre de forma tão tranquila. Nóvoa (2005) destaca que a utilidade e importância da História da Educação e seus temas estão sempre passando por questionamentos. Atendendo a esta necessidade de justificação, um bom ponto de partida é considerar a sincronicidade existente entre os sistemas educativo e social.

A educação é um elemento estruturante da organização das sociedades, razão pelo qual o estudo de sua história torna-se central para a compreensão destas e de seus modos educacionais. Stephanou e Bastos (2004) ressaltam que a História da Educação permite analisar o processo pelo qual as mais diferentes sociedades elaboram a si mesmas, como em cada época o ensino foi concebido em função "do real existente e suas contradições" (Stephanou; Bastos, 2004, p. 422).

\footnotetext{
${ }^{2}$ Por autônomas entendo as casas que se mantêm financeira e administrativamente por conta própria, sem vínculos com nenhuma universidade e nas quais a captação dos recursos cabe aos estudantes moradores. As autogeridas são aquelas que adotam o modelo de autogestão, independente de possuírem ou não uma instituição mantenedora.
} 
A História da Educação favorece, por um olhar mais global e contextualizado dos fenômenos, uma reflexão plural e crítica dos saberes, práticas educativas e pedagógicas. Para Nóvoa (2005) ela é capaz de pôr em cheque, por um ceticismo saudável, os procedimentos que se apresentam como inovadores e revolucionários, jogando-os em uma perspectiva histórica, além de possibilitar que pessoas e comunidades possam atribuir significado ao seu trabalho educativo.

Certeau (2013) destaca que cada estudo ou abordagem possui uma singularidade, que deve ser valorizada, pois emprega seus métodos próprios e carrega sua função social e convicções fundamentais. Cada discurso inscreve-se ao lado de outros discursos e "enquanto falam da história, estão sempre situados na história" (p. 4). Isso, contudo, não deve levar a pensar a História como um discurso maior, como um contexto, que englobe todos os demais. Para o autor os discursos "são históricos porque ligados a operações e definidos por funcionamentos" (p. 4). É neste sentido que a História da Educação se afirma como campo de pesquisa e de saberes.

O pesquisador que realizar um levantamento sobre a moradia estudantil como tema de pesquisa da produção acadêmica brasileira e portuguesa poderá observar que são raros os trabalhos existentes, além de haver uma predominância de abordagens pelo viés da assistência estudantil, de questões psicológicas e relacionadas à saúde dos moradores, como hábitos alimentares e consumo de drogas.

Mesmo em Coimbra, marcada pela vivência universitária e possuidora de inúmeras repúblicas estudantis em sua paisagem urbana, afora os estudos saudosistas, são escassas as pesquisas sobre a temática que ora discuto. Segundo Prata (2002), há pouca disposição, por parte dos historiadores, pelos assuntos relacionados à comunidade estudantil, aquela fora dos muros da universidade, aí incluídas as repúblicas, o que pode estar relacionada ao fato "não só de sua documentação se encontrar bastante dispersa, mas também à ausência de um roteiro sistemático de fontes e bibliografia" (p. 254).

É neste sentido que procuro apresentar três casas autônomas de Porto Alegre, pensando as suas potencialidades enquanto objeto de pesquisa, fontes e questões candentes. Tácitas e marginais estas organizações estudantis, que passaram ao largo da institucionalidade universitária e muitas vezes do próprio movimento estudantil formal, têm histórias a serem contadas, no sentido de uma multiplicação das imagens do estudante universitário de tempos passados e do presente.

\section{Casas autônomas de Porto Alegre}

Em Porto Alegre as origens do que hoje chamamos de ensino superior datam do final do século 19 e início do século 20. Em 1896 foi criada a Escola de Engenharia, em 1898 a Faculdade Livre de Medicina e Farmácia junto a qual, no mesmo ano, passou a funcionar a Faculdade de Odontologia. Em 1900 foi criada a Faculdade Livre de Direito e em 1910 o instituto de Agronomia e Veterinária (Oliveira; Licht, 2004).

$\mathrm{Na}$ lógica de que a questão da moradia estudantil é intrínseca à universidade, geradora de movimentos de jovens estudantes vindos de diversas partes do Estado para a capital em busca do grau superior, podemos inferir que estão também aí as origens das primeiras organizações coletivas de habitação estudantil. 
Embora a Ceuaca seja a primeira associação formal para esta finalidade em Porto Alegre, a ideia das repúblicas de estudante parece já estar presente antes de sua fundação em 1934, como demostra esta matéria da Revista do Globo:

Antigamente, os estudantes resolviam o problema por meio das famosas e inesquecíveis "repúblicas", nas quais viviam em comum inúmeros rapazes dotados de muitos ou poucos recursos. Vivendo e estudando em "repúblicas", formaram-se muitas gerações de estudantes que, mais tarde, se tornariam políticos, médicos, engenheiros, banqueiros e escritores de destaque em todo o País. (Palha, 1944, p.25)

Segundo Palha (1944), com o tempo as repúblicas foram desaparecendo. Como diagnóstico para o fenômeno o autor atribui a oferta de pensões familiares em diversas partes da cidade a preços módicos. Além disso, destaca que as repúblicas adquiriram uma fama afugentadora e os estudantes pobres, que necessitavam trabalhar para levar seus estudos, não encontravam nas repúblicas o devido descanso. Foi neste contexto que o autor situa as movimentações em favor de uma casa do estudante.

\section{Casa do Estudante universitário Aparício Cora de Almeida - Ceuaca}

Em 1931, concomitante com as discussões sobre a formação de uma Universidade em Porto Alegre, tomou corpo, entre os estudantes da Faculdade Livre de Direito ${ }^{3}$, a causa da moradia estudantil. Em 1933 o Centro Acadêmico deste curso assumiu a mobilização para construir o que então pretendiam chamar Casa do Estudante Pobre (Silva, 2004). Para esta finalidade organizou-se uma caravana para percorrer o interior do Rio Grande do Sul, encenando uma peça de teatro, além de organizarem festas em Porto Alegre com o objetivo de angariar fundos para a obra. No entanto, o objetivo da construção do prédio para a casa do estudante não foi alcançado. Na Revista do Globo destacou-se que a ideia

era uma realidade pequenina e hesitante, muito aquém dos seus objetivos. Por longo tempo, pode-se dizer, a "Casa do Estudante", foi apenas um título que encabeçava notícias nos jornais e que servia de motivo para infrutíferas festas de donativo e de blague para os próprios estudantes. (Palha, 1944, p. 25)

Ao invés da construção da sede própria uma comissão formada pelo Centro de Estudantes conseguiu, junto à Prefeitura de Porto Alegre, por intermédio do então prefeito Alberto Bins, a cedência de um imóvel situado na Rua Demétrio Ribeiro n. 1145 que,após uma completa reforma, passou a sediar a Casa do Estudante a partir $1^{\circ}$ de agosto de 1934. O prédio possuía dois pavimentos e tinha capacidade para abrigar cerca de 40 estudantes.

\footnotetext{
${ }^{3}$ A Faculdade Livre de Direito foi fundada em Porto Alegre em 17 de fevereiro de 1900. No ano de 1934 o então interventor do Estado, general Flores da Cunha, criou, por meio do decreto n. 5.758, a Universidade de Porto Alegre - UPA -, "formada pela integração da Universidade Técnica, com suas Escolas de Engenharia, Agronomia e Veterinária, da Faculdade de Medicina, com suas Escolas de Odontologia e Farmácia, da Faculdade Livre de Direito, com sua Escola de Comércio e o Instituto de Belas Artes" (Oliveira, Licht, 2004, p.47). No ano de 1950, ao ser integrada ao sistema federal de ensino superior, passou a se chamar Universidade do Rio Grande do Sul. 
A estrutura mantinha-se com o auxílio de pequenas subvenções públicas e de auxílios que partiam de iniciativas individuais, como as do professor Simch, da Faculdade de Direito, que colaborava com o custeio ao destinar parte dos seus vencimentos para este fim (Palha, 1944). Contudo, em 1938, a casa sofreu seu primeiro revés: a Prefeitura Municipal de Porto Alegre preparou um plano de remodelação da cidade, em que uma das ações previstas era a abertura de uma praça, hoje Praça Daltro Filho, em frente ao Cinema Capitólio, justamente onde ficava o prédio da Casa do Estudante, que seria demolido.

Após negociações com o então prefeito José Loureiro da Silva, os estudantes foram realocados para o Parque da Redenção, no pavilhão construído para expor os produtos típicos do Estado do Paraná utilizado na exposição de 1935, por ocasião das comemorações do Centenário Farroupilha. O jornal Correio do Povo publicou uma reportagem intitulada $A$ casa das vigas gementes, na qual descreve as condições na qual os estudantes se encontravam: "o pavilhão mede $240 \mathrm{~m}^{2}$. Seu forro é de aniagem, as paredes são de stuck e estão todas esburacadas; as divisões internas, algumas de taboa, outras de papelão, são feitas em forma de baias" (Correio do Povo, 25 set. 1938, p.19). Além disso, a iluminação era mal distribuída e não havia água encanada:

Quando o vento sopra um pouco forte - continua o nosso informante - o pavilhão mexe-se e as suas vigas gemem. Essa fragilidade toda - o estudante mostra com a mão o pavilhão - essa fragilidade toda, repito, acompanha o movimento do vento, e, vezes há que parece querer partirse, acabar-se, caindo sobre os estudantes, que não dormem. Nesses instantes horríveis - prossegue - partem preces mudas ao céu e Deus compadece-se deles e permite que essa carcaça permaneça de pé, para continuar abrigando-os, como único refúgio que possuem. (Correio do Povo, 25 set. 1938, p.19)

No ano de 1942 a Federação Universitária de Porto Alegre, por meio de mobilizações, alugou um prédio na Rua Duque de Caxias, n. 1707, para onde a casa foi transferida. Permaneceu sediada neste endereço até 1944 quando foi transferida, agora de forma definitiva, para o Edifício Almeida, na Rua Riachuelo n.1355.

O prédio, que consta ter sido um antigo hotel, foi doado pelo casal Israel Almeida e Maria Antônia Cora ao governo do Estado para que ali fosse sediada aquela que então passou a chamar-se Casa do Estudante do Rio Grande do Sul. A doação foi em homenagem ao filho do casal, Aparício Cora de Almeida ${ }^{4}$, militante da causa estudantil e misteriosamente morto em outubro de 1935.

\footnotetext{
${ }^{4}$ Aparício Cora de Almeida nasceu em Quaraí no ano de 1906, filho de Israel Almeida e Antoninha Cora de Almeida. Cursou Ciências Jurídicas e Sociais na Faculdade Livre de Direito de Porto Alegre em 1931, período em que presidiu o Centro dos Estudantes de Direito, dentro do qual se constituiu o movimento que daria origem a Ceuaca. Também foi presidente da Federação Acadêmica quando esta entidade atuou na preparação do movimento revolucionário de 1930, que levaria Getúlio Vargas ao governo. Formado, trabalhou como advogado criminalista em Porto Alegre e em cidades do interior do Estado. Foi membro do Partido Comunista Brasileiro e secretário-geral da ANL no Rio Grande do Sul. Há ainda registros de ativa participação junto às reuniões do Instituto da Ordem dos Advogados e no Conselho Deliberativo do Sport Club Internacional.
} 
No ano de 1959 a Casa foi reconhecida como uma entidade de utilidade pública estadual, ato referendado pelo então governador do Estado Leonel Brizola. O nome de Casa do Estudante universitário Aparício Cora de Almeida - Ceuaca - Ihe foi dado em 1961. Um ano depois ela foi reconhecida como entidade de utilidade pública federal (Silva, 2004).

A casa mantinha uma estrutura de assistência estudantil, com ambulatório - cujo atendimento era feito por estudantes de medicina em final de curso -, um consultório odontológico, lavanderia, cozinha com funcionários contratados, biblioteca, um salão de festas, além de dormitórios. Todos os serviços eram mantidos pelos moradores por meio das mensalidades que pagavam, por aportes eventuais da Universidade, pelos cooperativados, pessoas que usufruíam de todos os benefícios da Casa com exceção da moradia, e pelas festas, almoços e jantares com a finalidade de arrecadar recursos.

A Ceuaca teve significativa atuação nas atividades do movimento estudantil, servindo como ponto de encontro e confraternização entre estudantes e intelectuais da época. A década de 1980 ficou marcada pelo fato de mulheres serem aceitas como moradoras, uma vez que desde sua criação em 1934, recebia apenas estudantes do sexo masculino. Foi uma das últimas casas para estudantes universitários do Estado a implantar o sistema de moradia mista.

O prédio sede deteriorou-se ao longo dos anos, não havendo recursos para qualquer tipo de reforma. A situação chegou ao extremo nos anos 2000 , quando a casa foi sucessivamente interditada e sofreu inúmeros processos judiciais no sentido de evacuála. Houve movimentos de resistência dos moradores e mobilizações junto ao poder público. Em 2014, quando a instituição completou 80 anos, mediante negociação com o governo do Estado e o Ministério Público, chegou-se a um acordo sobre a reforma e os estudantes foram realocados para diversos imóveis na região central de Porto Alegre, mediante pagamento de aluguel social por parte do governo do Estado. Atualmente a Ceuaca presta auxílio de moradia a estudantes de graduação e pós-graduação carentes de recursos socioeconômicos e abriga cerca de cem moradores.

\section{Associação Casa de Estudantes Juventude Universitária Católica Casa 7 - JUC-7}

Outra casa que se mantem de forma autônoma é a Associação Casa de Estudantes Juventude Universitária Católica Casa 7 - JUC-7. Sua fundação data de 1949 no contexto das mobilizações da Juventude Universitária Católica por moradia estudantil, sendo que em Porto Alegre essas ações aconteceram a partir da Associação da Juventude Católica Ajuc. Foram criadas em todo país, com a participação direta da Igreja, 23 casas para servirem de moradia a estudantes universitários. Este movimento foi interrompido 1964 de modo que a última casa a manter o modelo inicial de organização foi fechada em 1975. A JUC-7, contudo, sobreviveu.

Em 1974 seus 53 moradores foram despejados do prédio chamado Castelinho, situado na rua Mostardeiro. Diante da situação a direção da casa vendeu o telefone e com esse dinheiro pagou a caução para o aluguel da sede na Rua da República, da qual, após algum tempo, também são expulsos, mudando-se para o bairro Partenon, na Vila Intercap, onde se abrigaram em uma construção de madeira por alguns anos, quando se intensificaram as mobilizações por um espaço próprio. 
Em 1987 a prefeitura, por lei municipal, faz a doação do terreno onde hoje está situado a sede da JUC-7. Por volta deste período a administração da casa recebeu, do governo do Estado, o valor de $\mathrm{Cz} \$ 1$ milhão. Em posse do dinheiro e do terreno os estudantes foram retirados pela prefeitura do imóvel na Intercap, indo morar na sede própria, na Rua Rivadávia Correia, n. 8, ainda inacabada. A JUC-7 encontra-se em funcionamento, servindo de moradia a estudantes universitários e pré-universitários de baixa renda, oriundos do interior do Rio Grande do Sul e de outros Estados do país.

\section{Casa Estudantil Universitária de Porto Alegre - Ceupa}

A terceira e última moradia autônoma é a Casa Estudantil Universitária de Porto Alegre - Ceupa, que nasceu da iniciativa de um grupo da Associação dos Ex-Alunos do Colégio Sinodal - Aeacs -, de São Leopoldo, que, em 1950, resolveu alugar um prédio em Porto Alegre, na Rua General Vitorino, e fundar a Casa do Ex-Aluno do Colégio Sinodal, tendo por objetivo abrigar os estudantes oriundos deste estabelecimento de ensino. Inicialmente contava com vinte vagas. Em 1954 foi adquirido um prédio, onde hoje fica uma das atuais sedes, na rua Sarmento Leite n. 1053. Isso foi feito por meio de uma campanha de arrecadação de fundos, numa ação entre amigos que contou com o sorteio de um automóvel.

A entidade passou por algumas transformações: chamou-se Casa do Estudante Evangélico do Rio Grande do Sul - Ceergs -, abrigando a partir de então não somente os ex-alunos do Colégio Sinodal, mas estudantes de todos os estabelecimentos evangélicos do Estado. Em 1960 passou a denominar-se Centro Evangélico Universitário do Rio Grande do Sul - Ceurgs. Com o aumento da demanda por moradia estudantil foi locado um prédio na Rua Sarmento Leite, n. 631, que funcionou como uma extensão da casa original, ampliando a capacidade da instituição em 21 vagas. Em decorrência de uma ação de despejo movida contra os moradores da Casa II, Rua Sarmento Leite, 631, e necessidade para uma residência para as estudantes do sexo feminino, em 1968 foram adquiridos dois novos prédios com recursos aportados pelo Sínodo Rio-Grandense, ligado a Igreja Evangélica de Confissão Luterana no Brasil, que passaram a abrigar a Casa II, na Rua José do Patrocínio, 648, e a Casa III, na Rua Luiz Afonso, 347.

Atualmente a Ceupa mantém a estrutura de três casas localizadas em Porto Alegre, com capacidade para abrigar 65 moradores efetivos, possuindo ainda, espaço para alojar temporariamente cerca de vinte moradores que estejam na cidade para participação de congressos ou seminários.

\section{Possibilidades da temática moradia estudantil universitária para a história da educação}

A origem das moradias estudantis é tão remota quanto a das primeiras universidades. O deslocamento em direção aos centros urbanos em busca de instrução universitária implica em providência de moradia. As múltiplas formas pelas quais estes espaços de habitação coletiva se organizaram e foram concebidos tornam difíceis uma leitura mais clara e precisa sobre este fenômeno. Organizações informais, registros e arquivos que se perderam para sempre, eis alguns dos motivos que tornam extremamente difícil um levantamento mais preciso. 
Prata (2002) localiza uma primeira ocorrência do termo república para estes ajuntamentos em Coimbra, no ano de 1836, e busca uma possível origem desta designação na semelhança da forma de governo e organização interna destas casas com a dos estados republicanos. Há ainda, no mesmo período, a ocorrência do termo Real República para designar estas habitações, o que pode, segundo Andrade (2014), ser uma referência aos dois regimes políticos - monarquia e república -, representando as várias correntes ideológicas de então, sendo, segundo interpretação da autora, um símbolo de liberdade e igualdade vivida entre os membros das casas.

As origens das casas estudantis brasileiras remontam à fundação da Faculdade de Medicina da Bahia, em 1808, no período da regência de Dom João VI. A partir daí foram criadas as Faculdades de Direito de São Paulo e Recife e, em 1876, a Escola de Minas, em Ouro Preto, durante o reinado de Dom Pedro II. A necessidade de que alunos e professores fixassem moradia na cidade, fez com que nela florescessem inúmeras repúblicas, que acabaram tornando-se o centro da vida estudantil e símbolo da região.

O modelo de organização destas casas, segundo Machado (2012), teve influências portuguesas, mais exatamente de Coimbra, berço das academias de Portugal e do Brasil, onde, no início do século 14, observa-se, segundo Prata (2002), o problema da moradia para os jovens que vinham até a cidade para a realização dos estudos universitários, com a escassez de casas e falta de condições das mesmas. Para tentar resolver o problema, que persiste até hoje, o governo português construiu casas no zoneamento urbano da Almedina, em Coimbra, afim de ser habitada por estudantes que eram selecionados por uma comissão nomeada pelo rei e mediante o pagamento pormenorizado de uma taxa.

No Brasil foi a partir da década de 1930 que a moradia estudantil passou a ser concebida como uma política de assistência a estudantes de baixa renda. As origens e formas de organização das casas de estudante, contudo, são bastante diversas. Além daquelas criadas pelas instituições universitárias, existem as nascidas por iniciativa dos próprios estudantes ou de outras organizações sociais, que se caracterizam pela autonomia e autogestão.

A precariedade e as situações limite, no entanto, parecem ser a regra nestes espaços. Em artigo publicado na Revista do Globo em 1944 tem-se um dimensionamento da situação da moradia estudantil na época. O texto, em tom de lamento pela situação em que os estudantes se encontravam, faz um paralelo da situação que se observava em Porto Alegre e traça comparações com as realidades de outros estados e países:

Eles [os estudantes] estão habituados a ler sobre entidades como "A Casa Internacional", ou "InternationalHouse", de Nova York, verdadeiro hotel de universitários, onde os pensionistas têm tudo, inclusive a mútua e produtiva convivência, por um preço ínfimo ou senão de graça. Sabem que as entidades similares no Rio e $\mathrm{S}$. Paulo dispõem de edifícios próprios, amplos e modernos, com capacidade para acolher um grande número de rapazes. E é mais ou menos isto que desejam os estudantes do Rio Grande: um grande edifício para a sua sede, um restaurante modelo, uma rica biblioteca, uma sala de conferência para recepcionar as missões de visitantes e várias outras coisas indispensáveis. Só então, depois de formados, eles não terão saído da Universidade com uma triste experiência da vida como acontece hoje, quase sempre com saúde abalada e prematuramente fatigados para o exercício da profissão aprendida. (Revista do Globo, n. 354, jan. 1944, p.24) 
Embora associadas à uma ideia de assistência estudantil as casas nem sempre são concebidas desta forma. No contexto internacional tem-se o exemplo da Residencia de estudiantes, em Madrid, fundada em 1910 e que foi o primeiro centro cultural da Espanha, constituindo-se em um espaço de trocas e criação artística e científica. Um espaço confortável, aberto à criação, ao pensamento e ao diálogo interdisciplinar, para onde os estudantes aportavam por escolha própria, sem que estivesse posta a questão socioeconômica. Propunha-se um espaço complementar ao ensino universitário, para estudos e criação.

A Residencia também acolhia as vanguardas internacionais do pensamento, tornando-se um foco de disseminação da modernidade na Espanha, tendo despontado, entre os seus moradores, muitas das principais figuras da cultura espanhola do século 20 , como o poeta Federico Garcia Lorca e o pintor Salvador Dalí, por exemplo. Foi, ainda, um fórum de discussão e divulgação da vida intelectual da Europa entre guerras, com teses apresentadas diretamente pelos seus protagonistas.

No Brasil Machado (2007) destaca a experiência da Universidade Estadual de Campinas, instituição que possui, em relação à moradia estudantil, uma concepção que ultrapassa a da assistência e as concebe como espaço de discussão sobre questões acadêmicas, interdisciplinares, de estudos e produção intelectual.

Outro aspecto da realidade brasileira a ser destacado são as mobilizações que ocorreram em prol da causa da moradia estudantil. Constitui-se numa das principais pautas do movimento de estudantes formalmente organizado, mas também de organizações que pleiteiam especificamente questões relacionadas às casas. Neste sentido, organizou-se a Secretaria Nacional de Casas de Estudantes - Sence ${ }^{5}$-, que promove anualmente os Encontros Regionais de Casas de Estudante - Erece - e o Encontro Nacional de Casas do Estudante - Ence.

Pensando as casas como potenciais temas de pesquisa cabe referir as inúmeras fontes por elas produzidas. Em diferentes graus de conservação e organização, estas organizações estudantis geraram inúmeros documentos, como atas das assembleias gerais, atas de conselhos deliberativos, documentação contábil, fichas de moradores, estatutos e regimentos internos, correspondências com outras instituições e com o poder público, autobiografias escritas pelos candidatos no momento da inscrição para o processo seletivo de novos moradores, fotografias, livros e revistas, recortes de jornal. Estes materiais podem ser importantes subsídios para historiadores e pesquisadores em geral.

A título de exemplo cito o caso do arquivo da Ceuaca. Em agosto de 2014, logo após o remanejo dos moradores do prédio que sediava a casa, devido às precárias condições em que este se encontrava, a diretoria da instituição foi notificada, pela Procuradoria Geral do Estado do Rio Grande do Sul, de que o prédio seria lacrado, tendo-Ihes sido concedido um prazo menor de 24 horas para que os moradores retirassem tudo o que nela ainda se encontrasse. O que tivesse ficado para trás no processo de mudança seria levado para galpões do governo ou descartado, inclusive o arquivo.

Ao tomar conhecimento desta situação emergencial, passei a fazer contato com

\footnotetext{
${ }^{5}$ A Secretaria Nacional de Casas de Estudantes é um movimento social autônomo, independente e organizado de forma horizontal por um colegiado. É formada nos encontros nacionais, composta por coordenadores eleitos no encontro regional, sendo cinco representantes de cada região. Ver $<$ http://sencebrasil.redelivre.org.br/44-2/>. Acesso em 27 ago. 2016. 
inúmeras instituições de guarda de documentos e universidades de Porto Alegre e região metropolitana. Na ocasião, o Arquivo Histórico do Memorial do Rio Grande do Sul acolheu a documentação. Um dia antes de a casa ser definitivamente lacrada contratei um caminhão de frete e, com a ajuda de dois dos moradores, tiramos o material do prédio da Ceuaca e o levamos até o seu novo abrigo. Atualmente o acervo encontra-se em processo de higienização e catalogação, devendo em breve estar disponível para pesquisas.

Já o acervo da Ceupa encontra-se guardado na própria Casa, porém não organizado, de modo que o seu manuseio se constituirá em árdua tarefa para o pesquisador. A documentação da JUC-7, por sua vez, é menos numerosa, uma vez que boa parte parece ter sido extraviada ou simplesmente descartada. Podem ter contribuído para isto, os despejos e as inúmeras mudanças de sede que a instituição enfrentou.

É possível perceber, a partir das fontes elencadas, sem prejuízo de outras que venham a ser localizadas ou produzidas, como as narrativas de memória oral, a potência destas para as pesquisas localizadas no campo da História da Educação, em especial na perspectiva da História Cultural. Ainda, e de acordo com a concepção de que um dos papéis da história é o de escriturar o passado (Certeau, 2011), acredito ser relevante a publicação ${ }^{6}$ das histórias e das memórias destas moradias, tácitas e marginais. Observese que a força e o sentido que emergem de seu caráter de autonomia financeira e administrativa, também são a sua fraqueza e fragilidade, visto que a ausência de uma instituição mantenedora as situa numa situação limite permanente.

\section{Considerações finais}

Se por um lado a escassez de trabalhos acadêmicos sobre moradia estudantil universitária dificulta a realização de pesquisas que tenham estes espaços como objetos, por outro, reforça a sua importância. Deste modo e a partir das considerações aqui apresentadas, defendo a necessidade de maiores estudos no campo da História da Educação sobre o tema. Com fontes orais, escritas ou imagéticas, produzidas no âmbito destas sociabilidades, é possível refletir como a experiência universitária foi vivida e significada na formação pessoal dos grupos em questão, suas respectivas histórias institucionais, suas relações dialógicas dentro de um sistema educativo mais amplo.

A leitura dos levantamentos realizados nas fontes relacionadas pode situar, numa configuração inteligível, a formação social, as práticas, os saberes, as estratégias e discursos de resistência que possibilitaram a manutenção destes modelos de organização durante períodos determinados. Contribui-se desta forma para multiplicar as imagens sobre o ser estudante universitário em lugares e temporalidades específicas.

É preciso buscar, pela explosão de vida, o contraditório de registros e relatos aparentemente insignificantes, corriqueiros, singulares, buscando tirar deles o máximo de sentido (Farge, 2009). O tamanho de um acontecimento está menos na sua grandeza e notoriedade factual do que em detalhes que possibilitem novas leituras do mundo, das

\footnotetext{
${ }^{6}$ A exceção é um trabalho editado em 2004 pela Universidade Federal do Rio Grande do Sul - SILVA, Ângelo Ronaldo Pereira da (org.). As casas de estudante da Ufrgs. Porto Alegre: Ufrgs, 2004 - por ocasião dos seus 70 anos, não foi localizada nenhuma publicação acerca desta temática. As casas aqui apresentadas possuem como única fonte historiográfica de seu passado os breves históricos apresentados em seus sites eletrônicos.

\begin{tabular}{l|l} 
Hist. Educ. (Online) & Porto Alegre
\end{tabular}

v. 21

ก. 51

Jan./abr., 2017

p. $435-448$
} 
relações sociais, dos valores de um determinado período da história. Estas leituras poderão contribuir, entre outras coisas, para a ressignificação do espaço Casa de Estudante para além das abordagens mais tradicionais, inscrevendo-o no universo das sociabilidades universitárias e na História da Educação, como lugar de trocas culturais, de aprendizagens, de luta política e organização estudantil.

\section{Referências}

ANDRADE, Inês Bernardo Lopes de. Repúblicas universitárias: uma estratégia para a regeneração urbana de Coimbra. Coimbra: Universidade de Coimbra, 2014. $137 f$. Dissertação (mestrado Integrado em Arquitetura). Universidade de Coimbra.

BOSI, Ecléa. O tempo vivo da memória: ensaios de psicologia social. São Paulo: Ateliê, 2003.

BURKE, Peter. O que é história cultural? Rio de Janeiro: Zahar, 2008.

CARDOSO, Ciro Flamarion; VAINFAS Ronaldo. Domínios da história. Rio de Janeiro: Elsevier, 1997.

CARREIRO, Teresa; MADEIRA, Margarida. Um por cem: um olhar sobre as repúblicas de Coimbra. Lisboa: Afrontamento, 2009.

CERTEAU, Michel de. A escrita da história. Rio de Janeiro: Forense-Universitária, 2013.

CHARTIER, Roger. A história cultural: entre práticas e representações. Lisboa: Difel, 1990.

CHARTIER, Roger. A história: a leitura do tempo. São Leopoldo: Unisinos, 2008, p.163178.

CUNHA, Maria Teresa Santos. Nas margens do instituído: memória/educação. Hist. Educ. (Online) Porto Alegre: Asphe, v. 3 n. 5, 1999, p. 23-38.

FARGE, Arlette. O sabor do arquivo. São Paulo: Edusp, 2009.

GARRIDO, Edleusa Nery; MERCURI, Elizabeth Nogueira Gomes da Silva. A moradia estudantil universitária como tema na produção científica nacional. Revista Semestral da Associação Brasileira de Psicologia Escolar e Educacional, São Paulo, v. 17, n. 1, 2013, p. 87-95.

HALBWACHS, Maurice. A memória coletiva. São Paulo: Centauro, 2003.

HALL, Stuart. A centralidade da cultura: notas sobre as revoluções de nosso tempo. Educação \& Realidade. Porto Alegre, v. 22, n. 2, 1997, p. 15-46.

LOPES, Eliane Marta Teixeira; GALVÃO, Ana Maria de Oliveira. Território plural: a pesquisa em história da educação. São Paulo: Ática, 2010.

MACHADO, Juciára Teixeira. Em busca de um mesmo CEU: estudo antropológico sobre (ex)moradores da casa do estudante da Universidade Federal de Santa Maria. Santa Maria: UFSM, 2012. 191f. Dissertação (mestrado em Ciências Sociais). Programa de PósGraduação em Ciências Sociais, Universidade Federal de Santa Maria.

MACHADO, Otávio Luiz. Repúblicas estudantis de Ouro Preto e Mariana: percursos e perspectivas. Frutal: Prospectiva, 2014.

MAGALHÃES, Justino Pereira de. Tecendo nexos: história das instituições educativas. Bragança Paulista: USF, 2004. 
MENEZES, Ulpiano. A História cativa da memória: para um mapeamento da memória no campo das Ciências Sociais. Revista Inst. Est. Bras, São Paulo, v. 1, n. 34, 1992, p. 9-24.

NOVOA, António. Carta a um jovem historiador da educação. Historia y Memoria de la Educación, Sedhe, n. 1, 2015, p. 23-58.

NÓVOA, António. Por que história da educação? In: BASTOS, Maria Helena e STEPHANOU, Maria. Histórias e memórias da educação no Brasil. Petrópolis: Vozes, 2005, p. 9-13.

OLIVEIRA, Carmem Regina de; LICHT, Flávia Boni. Ufrgs 70 anos. Porto Alegre: Ufrgs, 2004.

PALHA, Juliano. A Casa do Estudante. Revista do Globo, n. 354, 1944, p. 25.

PEREIRA, Marcos Villela. A escrita acadêmica: do excessivo ao razoável. Rev. Bras. Educ. [online]. Porto Alegre, v. 18, n. 52, 2013, p. 213-244.

PESAVENTO, Sandra Jatahy. Fronteiras da história: uma leitura sensível do tempo. São Leopoldo: Unisinos 2008, p.179-190.

PESAVENTO, Sandra Jatahy. História e história cultural. Belo Horizonte: Autêntica, 2008.

POLLAK, Michael. Memória e identidade social. Estudos Históricos, Rio de Janeiro, v. 5, n. 10, 1992, p. 200-212.

PRATA, Manuel Alberto Carvalho. Academia de Coimbra (1880-1926): contributo para a sua história. Coimbra: Universidade de Coimbra, 2002.

REVISTA DO GLOBO.A casa do estudante, n. 354, jan. 1944, p. 21-27.

RICOUER, Paul. A memória, a história, o esquecimento. Campinas: Unicamp, 2007.

SILVA, Ângelo Ronaldo Pereira da (org.). As casas de estudante da Ufrgs. Porto Alegre: Ufrgs, 2004.

STEPHANOU, Maria; BASTOS, Maria Helena Camara. História, memória e história da educação. In: STEPHANOU, Maria; BASTOS, Maria Helena Camara. Histórias e memórias da educação no Brasil. Petrópolis: Vozes, 2005, p. 416-419.

THONSON, Alistair. Memórias de Anzac: colocando em prática a teoria da memória popular na Austrália. Revista História Oral, n. 4, 2001, p. 85-101.

MARCOS LUIZ HINTERHOLZ é estudante do curso de Mestrado em Educação da Universidade Federal do Rio Grande do Sul.

Rua Olavo Bilac, 289/303 - 90040-310 - Porto Alegre - RS - Brasil.

E-mail: marcosluiz4@gmail.com.

Recebido em 5 de julho de 2016.

Aceito em 22 de novembro de 2016. 